J. Lake Sci. (湖泊科学) , 2013, 25(5): 681-687

http: //www. jlakes. org. E-mail : jlakes@niglas.ac.cn

(C) 2013 by Journal of Lake Sciences

\title{
不同干扰条件下纳帕海湿地植物群落优势种群的生态位
}

\author{
谭 苪 ${ }^{1}$, 李 伟 ${ }^{1}$,杨宇明 ${ }^{2}$, 杜 凡 ${ }^{1}$, 王 娟 ${ }^{2,3,4 * *}$ \\ ( 1 : 西南林业大学, 昆明 650224) \\ ( 2 :云南省林业科学院, 昆明 650201) \\ (3: 国家林业局云南珍稀濒特森林植物保护和繁育重点实验室, 昆明 650201) \\ ( 4 : 云南省森林植物培育与开发利用重点实验室, 昆明 650201)
}

\begin{abstract}
摘 要: 2011 年 $5 、 7 、 10$ 月在纳帕海湖滨湿地选择 3 种不同人为干扰生境类型,每个干扰生境布设 3 个固定样方,对湖滨 湿地植物群落中主要种群的空间生态位和季节特征进行研究. 结果表明: 在 3 种干扰水平维度上, 春、夏、秋 3 个季节湖滨 湿地植物生态位宽度指数前 4 位由大到小变化的顺序分别是: 春季: 绵毛酸模叶苶 $(0.9731)>$ 华扁穗草 $(0.8040)>$ 平车前 $(0.6468)>$ 毛果弹裂碎米荠 $(0.5021)$; 夏季:平车前 $(0.8674)>$ 荠 $(0.8581)>$ 华扁穗草 $(0.8440)>$ 绵毛酸模叶藅 $(0.7814)$; 秋季: 华扁穗草 $(0.9698)>$ 绵毛酸模叶苶 $(0.7730)>$ 平车前 $(0.6650)>$ 西南委陵菜 $(0.6647)$. 因此, 湖滨湿 地植物的生态位宽度在不同干扰水平上会随着季节的变化出现显著的改变. 同样,生态位重叠和生态位分化随着季节的 变化也会发生明显的改变,其中春、秋季的生态位重叠程度低, 分化程度高, 且春季较秋季略强, 而夏季的生态位重叠程 度高且分化程度低. 这些结果为揭示纳帕海湖滨湿地植物群落格局与动态及人为干扰影响生物多样性的生态过程提供 了基础资料, 同时为进一步深人研究不同人为干扰下湖滨湿地植物群落中主要种群敏感性反应的规律提供了科学依据.
\end{abstract}

关键词: 纳帕海湿地;干扰;生态位宽度;生态位重叠

\section{Niche characteristics of dominant species in Napahai wetland plant communities under different disturbance regimes}

\author{
TAN Rui ${ }^{1}$, LI Wei ${ }^{1}$, YANG Yuming ${ }^{2}$, DU Fan ${ }^{1} \&$ WANG Juan ${ }^{2,3,4}$ \\ ( 1 : Southwest Forestry University, Kunming 650224, P. R. China) \\ (2: Yunnan Academy of Forestry, Kunming 650201, P. R. China) \\ (3: Yunnan Laboratory for Conservation of Rare, Endangered and Endemic Forest Plants, Public Key Laboratory of the State \\ Forestry Administration, Kunming 650201, P. R. China) \\ (4: Key Laboratory of Forest Plant Cultivation and Utilization, Yunnan Academy of Forestry, Kunming 650201, P. R. China)
}

Abstract:This study investigated the spatial and seasonal niche characteristics of the dominant wetland plants in Napahai wetand. Under each disturbance regime, three plots were selected in 2011, and the data were collected in May, July, and October of the year. The results showed that there was a seasonal variation in species niche values under three different disturbance regimes. In spring, the order of the variation in niche breadth (from the highest to the lowest) is Polygonum lapathifolium $(0.9731)>$ Blysmus sinocompressus $(0.8040)>$ Plantago depressa $(0.6468)>$ Cardamine impatiens $(0.5021)$. In summer, the order is changed into Plantago depressa $(0.8674)>$ Cardamine impatiens $(0.8581)>$ Blysmus sinocompressus $(0.8440)>$ Polygonum lapathifolium (0.7814). In fall, the order is Blysmus sinocompressus $(0.9698)>$ Polygonum lapathifolium $(0.7730)>$ Plantago depressa $(0.6650)>$ Potentilla fulgens $(0.6647)$. Similarly, niche overlap and niche differentiation also alter remarkably with seasons. The lowest niche overlap and the highest niche differentiation occur in spring and fall, whereas the highest niche overlap and the lowest niche differentiation occur in summer. Our results provide important information in regard to plant community composition,

* 国家自然科学基金项目 (U0933601)、国家重点基础研究发展计划“973”项目 (2010CB434807)、云南省中青年学术 技术带头人后备人才培养项目 (2010CI016) 和云南省教委湿地生态学创新团队项目联合资助. $2012-11-30$ 收 稿;2013-03-08 收修改稿. 谭芮,女,1987 年生,硕士研究生;E-mail : tr13997761867@ 163.com.

** 通信作者;E-mail:schima@ 163.com. 
structure, dynamics, and diversity in Napahai wetland under different disturbance regimes, and help the understanding of the sensitivity of varying wetland plants in responses to different disturbances.

Keywords: Napahai wetland; disturbance; niche breadth; niche overlap

自从 Grinnell 将 “生态位” (niche) 定义为物种在环境中的最后分布单位以来, 有关生态位的研究一直是 国内外学者们关注的热点, 有关生态位理论 ${ }^{[1-5]}$ 、生态位测度 ${ }^{[6-10]}$ 以及生态位应用 ${ }^{[11-20]}$ 已有大量报道. 目前, 生态位理论研究中的一个重要内容是对生态位宽度和生态位重叠的定量计测 ${ }^{[21-23]}$. 研究种群生态位, 了解 各种群在群落中的地位和作用以及种群间的相互关系对植被资源的保护和恢复等具有重要意义 ${ }^{[24]}$.

干扰在影响物种的相互关系及分布格局过程中起着重要的作用. 干扰总是作用于一定的生态学过程, 通过干扰力介人、干预并渗透到各生态因子之间的相互作用间去, 而干扰所产生的生态效应也总是通过生 态过程上的反馈效应表现出来. 有研究认为 ${ }^{[21]}$, 干扰的一个突出作用是导致生态系统中各类资源的改变和 生态系统结构的重组. 干扰对生态环境的影响有利有弊, 其作用效果不仅取决于干扰本身的性质, 还取决于 干扰作用的客体, 适度的干扰可以促进生物多样性和生物资源的保护. 因此, 基于生境的不同干扰水平是影 响植物空间分布的重要因素. 干扰同时也具有一定的尺度效应, 以不同的研究尺度考察某一相同性质的干 扰, 所表现的干扰性质、特征及效应也不一定相同. 通过干扰效应的分析, 可以更好地探究干扰的性质、特征 及发生、发展规律. 然而, 目前探索干扰作用在不同的时间和空间尺度上对湿地植物群落的影响方面的研究 还比较少.

本研究通过对纳帕海湖滨固定样地植物群落不同季节的调查研究, 并对不同种群的生态位宽度及其之 间的生态位重叠度等进行分析, 以揭示不同季节、不同干扰条件下纳帕海湿地湖滨植物群落的生态位变化 规律, 为进一步研究生态系统稳定性提供依据, 对探讨高原湖滨植物群落功能的恢复和保护具有重要的理 论意义和实践意义.

\section{1 研究区概况}

纳帕海国际重要湿地 $\left(27^{\circ} 49^{\prime} \sim 27^{\circ} 55^{\prime} \mathrm{N}, 9^{\circ} 37^{\prime} \sim 99^{\circ} 43^{\prime} \mathrm{E}\right)$ 地处云南西北部香格里拉县境内, 青藏高原 的东南缘横断山腹地, 海拔 $3260 \mathrm{~m}$, 为我国低纬度高海拔湿地的独特类型, 属云南海拔最高和纬度最北的高 原湖泊之一, 也是沼泽化较为严重和退化较为典型的湿地 ${ }^{[25]}$. 该区气候属寒温带高原季风气候区西部型季 风气候, 全年盛行南风和南偏西风, 干湿季节分明, 6-10 月为雨季, 11 月至次年 5 月为明显干季, 降水少, 干旱突出. 纳帕海湿地周边居住有 14 个自然村、3000 多藏民族, 他们主要通过放牧、旅游服务和青稞种植等 方式获取经济收人, 因此, 纳帕海放牧现象十分严重, 加之旅游开发和无序旅游的影响, 形成放牧啃食和旅 游践踏的干扰在整个地区都存在. 传统上当地居民取块状草皮做护墙, 加之家猪放养在取过草皮的地方受 食翻拱, 这些不同类型的干扰对纳帕海湖滨植物群落的种群数量及其相互关系产生了深远的影响.

\section{2 研究方法}

\section{1 材料收集与整理}

依据纳帕海高原湖滨湿地受到的不同干扰类型, 选择有代表性地段, 分别设置固定样地, 并于 2011 年 5.7 和 10 月展开调查. 调查方法为在这些固定样地中随机布设 $1 \mathrm{~m} \times 1 \mathrm{~m}$ 的样方 (干扰样地的情况见表 1 ), 每个干扰类型设置 3 个样方. 调查内容包括: 植物名称、植物种数、株数、盖度、高度、生物量等. 将调查的每 块样地的每种植物的密度、盖度及出现频度换算成相对值, 并计算每种植物的重要值. 表 2 为整理后的 3 个 资源位不同季节的 15 种主要物种重要值及其生态因子.

\section{2 计算与分析}

以 3 种干扰水平上及春、夏、秋 3 个季节湖滨湿地植物取样地段为一维资源状态. 依次选出如表 2 的 3 个资源位, 在各资源位上计算各种群的重要值, 并运用生态位公式对生态位宽度和重叠度进行定量计算与 分析 ${ }^{[19]}$.

2.2 .1 生态位宽度 生态位宽度采用 Levins 的生态位宽度指数的计算方法 ${ }^{[13]}$,公式为: 


$$
B_{\mathrm{L}_{i}}=1 /\left(r \sum_{j=1}^{r} P_{i j}^{2}\right)
$$

式中, $B_{\mathrm{L}}$ 为物种 $i$ 的生态位宽度, 域值为 $[1 / r, 1] ; P_{i j}$ 是物种 $i$ 利用第 $j$ 资源占它利用全部资源位的比例; $r$ 为 资源位数. 其中:

$$
P_{i j}=n_{i j} / Y_{i}, Y_{i}=\sum_{i=1}^{n} n_{i j}
$$

式中, $n_{i j}$ 为物种 $i$ 在第 $j$ 资源位的重要值, $Y_{i}$ 为物种 $i$ 所利用全部资源位的重要值之和.

表 1 各样地基本概况

Tab. 1 General conditions of sampling plots

\begin{tabular}{lllll}
\hline 干扰类型 & 样方号 & 海拔 $/ \mathrm{m}$ & 经纬度 & 地表特征 \\
\hline 人工取草皮 & 纳 $07-2$ & 3277 & $27^{\circ} 51^{\prime} 56^{\prime \prime} \mathrm{N}, 99^{\circ} 39^{\prime} 35^{\prime \prime} \mathrm{E}$ & 人工取过草皮、永久早地、微积水、坚硬 \\
& 纳 $07-5$ & 3277 & $27^{\circ} 51^{\prime} 55^{\prime \prime} \mathrm{N}, 99^{\circ} 39^{\prime} 33^{\prime \prime} \mathrm{E}$ & 坚硬、浅积水、人工取过草皮 \\
& 纳 $07-8$ & 3277 & $27^{\circ} 51^{\prime} 55^{\prime \prime} \mathrm{N}, 99^{\circ} 39^{\prime} 29^{\prime \prime} \mathrm{E}$ & 干燥、坚硬、无积水、人工取过草皮、践踏痕迹 \\
猪拱 & 纳 $07-10$ & 3277 & $27^{\circ} 52^{\prime} 2^{\prime \prime} \mathrm{N}, 99^{\circ} 39^{\prime} 20^{\prime \prime} \mathrm{E}$ & 猪拱、永久陆地暂水淹、凹凸不平、基本无植物 \\
& 纳 $07-13$ & 3269 & $27^{\circ} 52^{\prime} 1^{\prime \prime} \mathrm{N}, 99^{\circ} 39^{\prime} 20^{\prime \prime} \mathrm{E}$ & 猪拱过、无积水、基本无植物 \\
& 纳 $07-16$ & 3268 & $27^{\circ} 52^{\prime} 1^{\prime \prime} \mathrm{N}, 99^{\circ} 39^{\prime} 20^{\prime \prime} \mathrm{E}$ & 猪拱过、凹凸不平、基本无植物 \\
旅游践踏、放牧 & 纳 $07-24$ & 3278 & $27^{\circ} 51^{\prime} 60^{\prime \prime} \mathrm{N}, 99^{\circ} 39^{\prime} 22^{\prime \prime} \mathrm{E}$ & 有大量践踏放牧过的痕迹 \\
& 纳 $07-25$ & 3278 & $27^{\circ} 52^{\prime} 14^{\prime \prime} \mathrm{N}, 99^{\circ} 39^{\prime} 9^{\prime \prime} \mathrm{E}$ & 有大量践踏放牧过的痕迹 \\
& 纳 $07-26$ & 3278 & $27^{\circ} 51^{\prime} 59^{\prime \prime} \mathrm{N}, 99^{\circ} 39^{\prime} 20^{\prime \prime} \mathrm{E}$ & 有大量践踏放牧过的痕迹 \\
\hline
\end{tabular}

表 2 湿地群落主要物种的重要值

\begin{tabular}{|c|c|c|c|c|c|c|c|c|c|c|}
\hline \multirow{2}{*}{ 序号 } & \multirow{2}{*}{ 种类 } & \multicolumn{3}{|c|}{ 春季 } & \multicolumn{3}{|c|}{ 夏季 } & \multicolumn{3}{|c|}{ 秋季 } \\
\hline & & III & I & II & III & I & II & III & I & II \\
\hline 1 & 绵毛酸模叶蓼 & 0.172 & 0.261 & 0.225 & 0.098 & 0.309 & 0.125 & 0.111 & 0.302 & 0.102 \\
\hline 2 & 华扁穗草 & 0.319 & 0.511 & 0.126 & 0.163 & 0.054 & 0.188 & 0.196 & 0.274 & 0.189 \\
\hline 3 & 沼泽煤菜 & - & - & - & 0.021 & 0.058 & 0.014 & 0.012 & 0.216 & 0.028 \\
\hline 4 & 早熟禾 & - & - & 0.021 & - & 0.068 & 0.068 & - & 0.209 & 0.020 \\
\hline 5 & 四川早熟禾 & 0.022 & - & - & - & - & - & 0.066 & - & 0.156 \\
\hline 6 & 毛果弹裂碎米荠 & 0.207 & - & 0.056 & 0.065 & - & 0.136 & 0.033 & - & - \\
\hline 7 & 西南委陵菜 & - & - & - & 0.216 & - & 0.050 & 0.086 & - & 0.077 \\
\hline 8 & 小花灯心草 & - & - & - & - & 0.159 & - & - & - & - \\
\hline 9 & 荠 & - & - & 0.137 & 0.043 & 0.076 & 0.124 & 0.012 & - & 0.015 \\
\hline 10 & 弹裂碎米荠 & - & - & - & - & 0.112 & - & - & - & - \\
\hline 11 & 小藜 & - & - & 0.011 & 0.106 & & - & - & - & - \\
\hline 12 & 云南高山豆 & - & 0.228 & - & - & - & - & - & - & - \\
\hline 13 & 百脉根 & - & 0.205 & - & - & - & - & - & - & - \\
\hline 14 & 败酱一种 & 0.115 & - & - & - & - & - & - & - & - \\
\hline 15 & 平车前 & 0.073 & - & 0.051 & 0.090 & 0.032 & 0.093 & 0.094 & - & 0.085 \\
\hline
\end{tabular}

Tab. 2 The important values of dominant wetland plant species

- 表示此种未出现,下同.

2.2.2 生态位重叠 生态位重叠是指一定资源序列上,两个物种利用同等级资源而相互重叠的情况,其计算 公式为 ${ }^{[10]}$ :

$$
L_{i h}=B_{\mathrm{L}_{i}} \sum_{j=1}^{r} P_{i j} \cdot P_{h j}
$$




$$
L_{h i}=B_{\mathrm{L}_{i}} \sum_{j=1}^{r} P_{i j} \cdot P_{h j}
$$

式中, $L_{i h}$ 为物种 $i$ 重叠物种 $h$ 的生态位重叠指数; $L_{h i}$ 为物种 $h$ 重叠物种 $i$ 的生态位重叠指数; $L_{i h} 、 L_{h i}$ 域 值为 $[0,1]$.

\section{3 结果与分析}

\section{1 生态位宽度结果和分析}

3.1 .1 生态位宽度结果 生态位宽度是度量植物种群对环境资源利用状况的尺度, 并且反映了一个物种对 环境的适应能力. 在 3 种干扰水平维度上, 春季湖滨湿地植物生态位宽度指数由大到小变化的顺序是: 绵毛 酸模叶荟 (Polygonum lapathifolium) $(0.9731)>$ 华扁穗草 (Blysmus sinocompressus $)(0.8040)>$ 平车前 (Plantago depressa) (0.6468) >毛果弹裂碎米荠 (Cardamine impatiens) $(0.5021)>$ 早熟禾 $($ Poa annua )、四川早熟 禾 (Poa szechuensis)、荠 (Capsella bursa-pastoris)、云南高山豆( Tibetia yunnanensis)、百脉根 (Lotus corniculatus)、败酱一种 (Patrinia sp.) (0.3333) (表 3). 在春季, 绵毛酸模叶蓼对环境的适应能力最强,在所有的资源 位都出现, 对资源的利用最充分. 华扁穗草对环境的适应能力次之, 也在所有的资源位都出现, 对资源的利 用也较为充分. 平车前、毛果弹裂碎米荠对环境的适应能力一般, 仅在两个生态资源位上出现, 对资源的利 用也一般. 早熟禾、四川早熟禾、荠、云南高山豆、百脉根和败酱一种对环境的适应能力很差, 仅在一个生态 资源位上出现,对资源的利用很差 (表 2).

在夏季为:平车前 $(0.8674)>$ 荠 $(0.8581)>$ 华扁穗草 $(0.8440)>$ 绵毛酸模叶苶 $(0.7814)>$ 沼泽蔊菜 (Rorippa palustris $)(0.7200)>$ 早熟禾 $(0.6666)>$ 毛果弹裂碎米荠 $(0.5926)>$ 西南委陵菜 (Potentilla fulgens $)(0.4790)>$ 小莍 (Chenopodium serotinum) $(0.4023)>$ 小花灯芯草 (Juncus articulatus)、弹裂碎米荠 (0.3333) (Cardamine impatiens) (表 3). 在夏季, 平车前对环境的适应能力最强, 在所有的生态资源位都出 现, 对资源的利用最充分. 荠、华扁穗草、绵毛酸模叶蓼和沼泽蔊菜对环境的适应能力次之, 也在所有的生态 资源位都出现, 对资源的利用也较为充分. 早熟禾、毛果弹裂碎米荠、西南委陵菜和小栳对环境的适应能力 一般, 仅在两个生态资源位上出现, 对资源的利用也一般. 小花灯芯草和弹裂碎米荠对环境的适应能力很 差,仅在一个生态资源位上出现,对资源的利用也很差(表 2).

在秋季为: 华扁穗草 $(0.9698)>$ 绵毛酸模叶苶 $(0.7730)>$ 平车前 $(0.6650)>$ 西南委陵菜 $(0.6647)>$ 荠 $(0.6533)>$ 四川早熟禾 $(0.5713)>$ 沼泽草菜 $(0.4579)>$ 早熟禾 $(0.3981)>$ 毛果弹裂碎米荠 $(0.3333)$ (表 3). 在秋季, 华扁穗草对环境的适应能力最强, 在所有生态资源位都出现, 对资源的利用最充分. 绵 毛酸模叶苶对环境的适应能力次之, 也在所有生态资源位都出现, 对资源的利用也较为充分. 平车前、 西南委陵菜、荠、四川早熟禾、沼泽蔊菜和早熟禾对环境的适应能力一般, 仅在两个生态资源位上出 现, 对资源的利用也一般. 毛果弹裂碎米荠对环境的适应能力很差, 仅在一个生态资源位上出现, 对资 源的利用很差 (表 2 ).

3.1 .2 生态位宽度分析 综上所述, 纳帕海高原湖滨湿地植物的生态位宽度在不同干扰水平上会随着季节 的变化出现显著的改变. 绵毛酸模叶苶、华边穗草、早熟禾、毛果弹裂碎米荠、荠、平车前都是 3 季生长的物 种. 其中, 绵毛酸模叶苶和华边穗草为广生态位型的主要物种, 其它物种均为狭生态位型. 它们可以在任何 干扰水平维度和季节里生长, 表明这些物种对环境的适应能力很强, 对各种资源的利用能力也很强, 而且在 群落中处于优势地位. 其他几种, 如平车前、早熟禾、毛果弹裂碎米荠和荠会在所有的季节出现, 但是却不能 在所有的干扰水平维度上出现. 沼泽蔊菜和西南委陵菜在夏季和秋季生长, 而四川早熟禾生长在春季和秋 季. 生态位宽度只占据一个生态资源位的种群不少, 云南高山豆、百脉根和败酱一种仅生长在春季, 小㥭、小 花灯心草和弹裂碎米荠仅生长在夏季, 这些物种都只在一个季节生长. 其中春季、夏季和秋季的生态位宽度 只占据一个生态资源位的种群分别占所有种群数的 $60 \%$ 、18\% 和 $11 \%$, 可见, 当前整个纳帕海湖滨湿地群落 具有多样性、复杂性、明显的优势种群, 各个种群的生态位宽度值表明了它们在群落中的地位与作用. 这些 变化的结果固然与不同种类的生态生物学特性分不开, 但不同季节可利用资源相对丰富度的变化和不同干 扰水平维度上可利用资源的再分配模式也具有重要作用. 


\section{2 生态位重叠结果和分析}

3.2 .1 生态位重叠结果 每个季节生态位重 叠指数最高的前 3 对分别为: 在春季群落主 要种群中, 毛果弹裂碎米荠 (6) 对四川早熟禾 (5) 的生态位重叠值为 $0.786\left(L_{h i}\right)$, 荠 (9) 对 毛果弹裂碎米荠 (6) 的生态位重叠值为 0.713 , 绵毛酸模叶蓼 (1) 对华扁穗草 (2) 的 生态位重叠值为 0.667 ; 在夏季群落主要种群 中, 平车前 (15) 对小花灯心草 (8)、弹裂碎米 荠 (10) 和沼泽草菜 (3) 的生态位重叠值分别 为 $0.785 、 0.785$ 和 0.508 ; 在秋季群落主要种 群中, 绵毛酸模叶苶对早熟禾 $(4)$ 和沼泽草菜 的生态位重叠值分别为 0.428 和 0.409 , 华扁 穗草对早熟禾的生态位重叠值为 0.393 (表 4). 春季和夏季前 3 对的重叠指数都很高, 这 说明这 3 个种对在春季和夏季对不同干扰水 平上的资源利用趋于一致, 而且能够共存. 而 在秋季的前 3 对的重叠指数比春季和夏季的 要小很多,说明秋季对生境中资源利用的趋 同性较弱.

不同季节群落主要种群生态位重叠值中
表 3 不同季节湿地植物群落主要种群的生态位宽度值

Tab. 3 The niche breadth of dominant wetland plant species varying with seasons

\begin{tabular}{lccc}
\hline \multirow{2}{*}{ 种类 } & \multicolumn{3}{c}{ 生态位宽度 $B_{\mathrm{L}}$} \\
\cline { 2 - 4 } & 春季 & 夏季 & 秋季 \\
\hline 绵毛酸模叶蓼 & 0.9731 & 0.7814 & 0.7773 \\
华扁穗草 & 0.8040 & 0.8440 & 0.9698 \\
沼泽蔊菜 & - & 0.7200 & 0.4579 \\
早熟禾 & 0.3333 & 0.6666 & 0.3981 \\
四川早熟禾 & 0.3333 & - & 0.5713 \\
毛果弹裂碎米荠 & 0.5021 & 0.5926 & 0.3333 \\
西南委陵菜 & - & 0.4790 & 0.6647 \\
小花灯心草 & - & 0.3333 & - \\
荠 & 0.3333 & 0.8581 & 0.6533 \\
弹裂碎米荠 & - & 0.3333 & - \\
小㢣 & - & 0.4023 & - \\
云南高山豆 & 0.3333 & - & - \\
百脉根 & 0.3333 & - & - \\
败酱一种 & 0.3333 & - & - \\
平车前 & 0.6468 & 0.8674 & 0.6650 \\
\hline
\end{tabular}

位置集中也不同, 在春季主要集中在 $0\left(L_{i h}\right.$ 和 $\left.L_{h i}\right)$, 所占的比例都为 $29 \%, 0$ 即完全不重叠, 这说明在春季对 不同干扰水平维度上的生境资源利用完全不同,即不存在资源利用竞争; 在夏季主要集中为 $0.2 \sim 0.3\left(L_{i h}\right)$ 和 $0.1 \sim 0.2\left(L_{h i}\right)$, 所占的比例都为 $31 \%$, 这说明很多物种的重叠指数不太大, 物种之间对资源利用的相似 度和竞争也不太大; 在秋季主要集中在 $0 \sim 0.1$ 和 $0.1 \sim 0.2$ 之间 $\left(L_{i h}\right)$ 和 $0.1 \sim 0.2\left(L_{h i}\right)$, 所占的比例分别为 $25 \% 、 25 \%$ 和 $31 \%$, 这比夏季物种的重叠指数还要低,说明物种之间对资源利用的相似度和竞争也就更加低 (表 5 ).

春、夏和秋季群落主要种群生态位重叠值大于 0.5 所占的比例分别为 9\% (4 对)、6\% (3 对) 和 0 , 这些 比例都非常低 (表 4、5). 这说明春季和夏季对不同干扰水平维度上的资源利用趋于一致的物种非常少,但也 还是存在, 而且能够共存; 而在秋天对不同干扰水平维度上的资源利用趋于一致而且能够共存的物种就更 加少了. 在不同干扰水平维度上, 春、夏、秋 3 个不同季节湿地湖滨植物最大限度的生态位重叠指数种对和 0 指数种对的种类均发生了显著变化: 春季湿地湖滨植物最大限度的生态位重叠指数有 32 种, 0 指数种对有 荠对华边穗草和四川早熟禾,云南高山豆对早熟禾、四川早熟禾、弹裂碎米荠和荠, 百脉根对四川早熟禾和 云南高山豆,败酱一种对早熟禾、荠、云南高山豆和百脉根 13 个种对,二者所占比例分别为 $71 \%$ 、 $29 \%$. 夏季 湿地湖滨植物最大限度的生态位重叠指数有 51 种, 0 指数种对有小花灯芯草和小荺对毛果弹裂碎米荠、西 南委陵菜 4 个种对, 二者所占比例分别为 $93 \%$ 、7\%. 秋天湿地湖滨植物最大限度的生态位重叠指数有 35 种, 0 指数种对仅有毛果弹裂碎米荠对早熟禾 1 个种对,二者所占比例分别为 $3 \% 、 97 \%$. 在春季有 21 个 0 指 数种对而在秋季最大限度的生态位重叠指数和 0 指数则分别为 4 和 1 个种对, 表明很多物种在不同的生境 里出现有关系,而夏季以后物种就慢慢地在各种生境都可以生长了.

3.2 .2 生态位重叠分析 综上所述, 春、夏、秋 3 个季节湖滨植物湿地的生态位重叠指数变化很大. 结果说 明, 在不同干扰水平维度上, 湖滨植物湿地的生态位重叠和生态位分化随着季节不同会发生明显的改变, 春、秋季的生态位重叠程度低、分化程度高, 春季较秋季略强; 夏季的生态位重叠程度高, 而分化程度低.

\section{4 结论}

1 ) 适应性:生态位宽度和生态位重叠值都反映出在纳帕海湿地中绵毛酸模叶蓼、华扁穗草、荠、平车前 
的适应性较强. 这些物种能在不同的季节和干扰条件下都能生活得很好.

表 4 干扰水平维度上湖滨湿地植物不同季节生态位重叠指数 *

Tab. 4 Niche overlap indices of wetland plant species varying with seasons

\begin{tabular}{|c|c|c|c|c|c|c|c|c|c|c|c|c|c|c|c|c|}
\hline 季节 & 序号 & 1 & 2 & 3 & 4 & 5 & 6 & 7 & 8 & 9 & 10 & 11 & 12 & 13 & 14 & 15 \\
\hline \multirow[t]{10}{*}{ 春季 } & 1 & & 0.667 & & 0.114 & 0.087 & 0.140 & & & 0.114 & & & 0.132 & 0.114 & 0.087 & 0.191 \\
\hline & 2 & 0.335 & & & 0.044 & 0.111 & 0.146 & & & 0.044 & & & 0.044 & 0.044 & 0.111 & 0.162 \\
\hline & 4 & 0.333 & 0.106 & & & 0 & 0.107 & & & 0.333 & & & 0 & 0.333 & 0 & 0.267 \\
\hline & 5 & 0.255 & 0.269 & & 0 & & 0.786 & & & 0 & & & 0 & 0 & 0.333 & 0.588 \\
\hline & 6 & 0.271 & 0.234 & & 0.071 & 0.262 & & & & 0.713 & & & 0 & 0.071 & 0.262 & 0.262 \\
\hline & 9 & 0.342 & 0.106 & & 0.333 & 0 & 0.107 & & & & & & 0 & 0.333 & 0 & 0.267 \\
\hline & 12 & 0.386 & 0.430 & & 0 & 0 & 0 & & & 0 & & & & 0 & 0 & 0 \\
\hline & 13 & 0.333 & 0.106 & & 0.333 & 0 & 0.107 & & & 0.333 & & & 0 & & 0 & 0.267 \\
\hline & 14 & 0.255 & 0.269 & & 0 & 0.333 & 0.395 & & & 0 & & & 0 & 0 & & 0.380 \\
\hline & 15 & 0.287 & 0.201 & & 0.138 & 0.196 & 0.276 & & & 0.138 & & & 0 & 0.138 & 0.196 & \\
\hline \multirow[t]{11}{*}{ 夏季 } & 1 & & 0.220 & 0.316 & 0.272 & & 0.129 & 0.093 & 0.194 & 0.287 & 0.194 & 0.219 & & & & 0.471 \\
\hline & 2 & 0.204 & & 0.176 & 0.199 & & 0.263 & 0.198 & 0.045 & 0.300 & 0.045 & 0.064 & & & & 0.138 \\
\hline & 3 & 0.343 & 0.206 & & 0.258 & & 0.103 & 0.103 & 0.208 & 0.267 & 0.208 & 0.236 & & & & 0.508 \\
\hline & 4 & 0.319 & 0.252 & 0.278 & & & 0.199 & 0.045 & 0.168 & 0.352 & 0.168 & 0.183 & & & & 0.395 \\
\hline & 6 & 0.171 & 0.375 & 0.125 & 0.224 & & & 0.187 & 0 & 0.345 & 0 & 0.012 & & & & 0.027 \\
\hline & 7 & 0.152 & 0.349 & 0.154 & 0.062 & & 0.231 & & 0 & 0.206 & 0 & 0.031 & & & & 0.067 \\
\hline & 8 & 0.454 & 0.113 & 0.449 & 0.335 & & 0 & 0 & & 0.268 & 0.333 & 0.364 & & & & 0.785 \\
\hline & 9 & 0.261 & 0.295 & 0.224 & 0.273 & & 0.238 & 0.115 & 0.104 & & 0.104 & 0.121 & & & & 0.260 \\
\hline & 10 & 0.454 & 0.113 & 0.449 & 0.335 & & 0 & 0 & 0.333 & 0.268 & & 0.364 & & & & 0.785 \\
\hline & 11 & 0.425 & 0.134 & 0.422 & 0.304 & & 0.018 & 0.037 & 0.302 & 0.258 & 0.302 & & & & & 0.152 \\
\hline & 15 & 0.207 & 0.328 & 0.182 & 0.193 & & 0.253 & 0.202 & 0.050 & 0.293 & 0.050 & 0.070 & & & & \\
\hline \multirow[t]{9}{*}{ 秋季 } & 1 & & 0.354 & 0.510 & 0.252 & 0.116 & 0.072 & 0.138 & & 0.135 & & & & & & 0.138 \\
\hline & 2 & 0.284 & & 0.182 & 0.161 & 0.166 & 0.099 & 0.194 & & 0.190 & & & & & & 0.194 \\
\hline & 3 & 0.409 & 0.385 & & 0.310 & 0.052 & 0.015 & 0.050 & & 0.054 & & & & & & 0.051 \\
\hline & 4 & 0.428 & 0.393 & 0.357 & & 0.036 & 0 & 0.028 & & 0.033 & & & & & & 0.028 \\
\hline & 5 & 0.158 & 0.281 & 0.042 & 0.025 & & 0.099 & 0.325 & & 0.346 & & & & & & 0.326 \\
\hline & 6 & 0.168 & 0.288 & 0.021 & 0 & 0.169 & & 0.351 & & 0.280 & & & & & & 0.349 \\
\hline & 7 & 0.162 & 0.283 & 0.035 & 0.017 & 0.279 & 0.176 & & & 0.324 & & & & & & 0.333 \\
\hline & 9 & 0.160 & 0.282 & 0.038 & 0.020 & 0.302 & 0.143 & 0.330 & & & & & & & & 0.330 \\
\hline & 15 & 0.161 & 0.283 & 0.035 & 0.017 & 0.280 & 0.175 & 0.333 & & 0.324 & & & & & & \\
\hline
\end{tabular}

*表 4 中种群序号与表 2 相同.

表 5 湿地植物群落生态位重叠分配格局

Tab. 5 The niche overlap range categories of wetland plant species

\begin{tabular}{llccccccccc}
\hline \multirow{2}{*}{ 季节 } & \multicolumn{8}{c}{ 范围 } \\
\cline { 3 - 10 } & & 0 & $0 \sim 0.1$ & $0.1 \sim 0.2$ & $0.2 \sim 0.3$ & $0.3 \sim 0.4$ & $0.4 \sim 0.5$ & $0.5 \sim 0.6$ & $0.6 \sim 0.7$ & $0.7 \sim 0.8$ \\
\hline 春季 & $L_{i h}$ 比例 & 0.29 & 0.04 & 0.20 & 0.22 & 0.22 & 0.02 & & & \\
& $L_{h i}$ 比例 & 0.29 & 0.16 & 0.24 & 0.11 & 0.11 & & 0.02 & 0.02 & 0.04 \\
夏季 & $L_{i h}$ 比例 & 0.07 & 0.11 & 0.20 & 0.31 & 0.20 & 0.11 & & 0.04 & \\
& $L_{h i}$ 比例 & 0.07 & 0.16 & 0.31 & 0.24 & 0.14 & 0.02 & 0.02 & \\
秋季 & $L_{i h}$ 比例 & 0.03 & 0.25 & 0.25 & 0.22 & 0.19 & 0.06 & & \\
& $L_{h i}$ 比例 & 0.03 & 0.33 & 0.28 & 0.05 & 0.28 & 0.03 & & & \\
\hline
\end{tabular}


2) 种间关系: 植物间的竞争现象在自然界中难以直接观察, 特别是湿地湖滨植物的种间和种内竞争更 是如此,所以深人分析共存物种之间在不同空间条件和不同季节的资源再分配问题对研究生态位与竞争的 关系显得非常重要. 就纳帕海湖滨湿地的研究来看, 上述湿地植物最大限度的生态位重叠指数种对和 0 指 数种对的种类在不同空间条件和不同季节存在明显区别, 这种区别从竞争的角度分析, 可以认为生态位重 叠和分化趋势有变化的种类, 其种间竞争程度较强; 反之, 则较弱. 一般认为, 竞争强度应当与在特定资源梯 度上所观察到的生态位重叠值呈正比 ${ }^{[19-21]}$. 而本研究特定资源梯度没有改变, 之所以出现在不同季节特定 资源梯度上最大限度的生态位重叠和分化的变化, 温度、降雨量和天气的变化都可能是影响因素. 因此, 可 利用资源在不同季节的变化是影响湿地植物种间竞争和生态位改变的重要因素.

3 ) 植被恢复:生态位宽度是一个生物所利用的各种资源之总和,生态位越宽该物种的特化程度就越小, 也就是说它更倾向于是一个泛化物种, 相反, 一个物种的生态位越窄, 该物种的特化程度就越强, 更倾向于 是一个特化物种 ${ }^{[25]}$. 就纳帕海湿地湖滨植物来看, 在不同空间条件与不同季节物种生态位宽度的变化不明 显 (表 3 ). 在纳帕海湿地中, 绵毛酸模叶蓼、华扁穗草、荠、平车前的生态位宽度值都比较大, 建议可以优先选 择这些物种进行湿地植被恢复.

4 ) 演替: 为猪拱和人工取草皮干扰后的演替研究奠定了一定的基础. 事实上, 干扰作用施加过后, 在植 被处于恢复的整个期间都伴随着演替过程, 因此需要较长时间进行深人研究.

致谢: 栗红林老师、马猛师兄、刘娟师姐和本科的师弟师妹们在野外调查、标本鉴定以及论文写作上给予了 帮助, 在此表示衰心的感谢.

\section{5 参考文献}

[ 1 ] 尚玉昌. 现代生态学中的生态位理论. 生态学进展, 1988,5(2):77-84.

[ 2 ] 牛克昌,刘怿宁, 沈泽吴等. 群落构建的中性理论和生态位理论. 生物多样性, 2009,17(6):579-593.

[ 3 ] 张光明,谢寿昌. 生态位概念演变与展望. 生态学杂志, 1997,16(6) :46-51.

[ 4 ] Chase JM, Belovsky GE. Experimental evidence for the included niche. American Naturalist, 1994, 143:514-527.

[ 5 ] Chase JM, Leibold MA. Ecological niches: linking classical and contemporary approaches. Chicago: University of Chicago Press, 2003.

[6] 金松岩,张 敏,杨 春.生态位理论研究论述. 内蒙古环境科学,2009,21(4):12-15.

[ 7 ] 李 杰,朱金兆,朱清科. 生态位理论及其测度研究进展. 北京林业大学学报,2003,25(1):100-107.

[8] 黄英姿. 生态位理论研究中的数学方法. 应用生态学报, 1994,5(3):331-337.

[ 9 ] 余世孝,奥罗西 L. 物种多维生态位宽度测度.生态学报, 1994,14(1) :32-39.

[10］李德志,石 强,藏润国等. 物种或种群生态位宽度与生态位重叠的计测模型. 林业科学, 2006,42(7):95-103.

[11] 朱德煌, 刘金福, 洪 伟等. 戴云山黄山松群落主要树种更新生态位研究. 热带亚热带植物学报, 2012,20(6): 561-565.

[12] 谢春平, 方 彦, 方炎明. 乌冈栋群落乔木层种群生态位分析. 中国水土保持科学, 2012,9(1):108-114.

[13] 刘金福,洪 伟. 格氏栲群落生态学研究——格氏栲主要种群生态位的研究. 生态学报, 1999,19(3):347-352.

[14] 苏志尧, 吴大荣,陈北光. 粤北天然林优势种群生态位研究. 应用生态学报,2003,14(1):25-29.

[15] 杨自辉,方峨天, 刘虎俊等. 民勤绿洲边缘地下水位变化对植物种群生态位的影响. 生态学报, 2007,27(11): 4900-4906.

[16] 韩晓卓, 张彦宇. 基于生态位构建的 n-种群集合种群动态分析. 生态学报,2008,28(7):3271-3276.

[17] 封 否,洪 伟, 吴承祯等. 武夷山黄山松林主要种群生态位特征. 山地学报,2008,26(3):308-316.

[18] 胡正华,钱海源,于明坚. 古田山国家级自然保护区甜槠林优势种群生态位. 生态学报,2009,29(7):3670-3677.

[19］胡正华,于明坚.古田山青冈林优势种群生态位特征. 生态学杂志,2005,24(10):1159-1162

[20］杨君珑,王 辉,孙栋元等. 子午岭油松林主要种群更新生态位研究. 林业资源管理,2006,6:51-56.

[21] 陈利顶,傅伯杰.干扰的类型、特征及其生态学意义.生态学报,2000,20(4):581-586.

[22] 付和平,武晓东,杨泽龙. 不同干扰条件下荒漠啮齿动物生态位特征. 生态学报,2005,25(10):2637-2643.

[23] 傅德平. 艾比湖湿地典型植物群落物种多样性及其优势种群生态位研究 [学位论文].乌鲁木齐: 新疆大学, 2008.

[24] 尚玉昌. 普通生态学:第 2 版. 北京: 北京大学出版社,2002:284-295.

[25] Putman RJ, Wratten SD 著. 王昱生等译. 生态学原理. 长春: 吉林科学技术出版社, 1994:133-164. 